\title{
A systematic review of economic evaluations of cardiac rehabilitation
}

\author{
Wai Pong Wong ${ }^{1,2^{*}+}$, Jun Feng ${ }^{3+}$, Keng Ho Pwee ${ }^{4}$ and Jeremy Lim ${ }^{5}$
}

\begin{abstract}
Background: Cardiac rehabilitation (CR), a multidisciplinary program consisting of exercise, risk factor modification and psychosocial intervention, forms an integral part of managing patients after myocardial infarction (MI), revascularization surgery and percutaneous coronary interventions, as well as patients with heart failure (HF). This systematic review seeks to examine the cost-effectiveness of CR for patients with Ml or HF and inform policy makers in Singapore on published cost-effectiveness studies on CR.
\end{abstract}

Methods: Electronic databases (EMBASE, MEDLINE, NHS EED, PEDro, CINAHL) were searched from inception to May 2010 for published economic studies. Additional references were identified through searching bibliographies of included studies. Two independent reviewers selected eligible publications based on the inclusion/exclusion criteria. Quality assessment of economic evaluations was undertaken using Drummond's checklist.

Results: A total of 22 articles were selected for review. However five articles were further excluded because they were cost-minimization analyses, whilst one included patients with stroke. Of the final 16 articles, one article addressed both centre-based cardiac rehabilitation versus no rehabilitation, as well as home-based cardiac rehabilitation versus no rehabilitation. Therefore, nine studies compared cost-effectiveness between centre-based supervised CR and no CR; three studies examined that between centre- and home based CR; one between inpatient and outpatient CR; and four between home-based CR and no CR. These studies were characterized by differences in the study perspectives, economic study designs and time frames, as well as variability in clinical data and assumptions made on costs. Overall, the studies suggested that: (1) supervised centre-based CR was highly cost-effective and the dominant strategy when compared to no CR; (2) home-based CR was no different from centre-based CR; (3) no difference existed between inpatient and outpatient CR; and (4) home-based programs were generally cost-saving compared to no $\mathrm{CR}$.

Conclusions: Overall, all the studies supported the implementation of CR for MI and HF. However, comparison across studies highlighted wide variability of $\mathrm{CR}$ program design and delivery. Policy makers need to exercise caution when generalizing these findings to the Singapore context.

\section{Background}

Cardiovascular diseases are a major cause of mortality and morbidity, contributing to about $30 \%$ of all-cause mortality and $10 \%$ of the total disability-adjusted lifeyears globally [1]. Although advances in medical therapy and revascularization surgery have improved outcome, reducing risk factors associated with cardiovascular

\footnotetext{
* Correspondence: WaiPong.Wong@SingaporeTech.edu.sg

${ }^{\dagger}$ Equal contributors

'Academic Programmes Division, Singapore Institute of Technology, 25

North Bridge Road, Singapore, Singapore

${ }^{2}$ Primary \& Community Care Division, Ministry of Health, 16 College Road,

Singapore, Singapore

Full list of author information is available at the end of the article
}

diseases remains an important strategy in lowering the global burden of disease [2]. Risk factor management is a core component of cardiac rehabilitation, which in turn forms part of the overall management of patients with cardiovascular diseases such as coronary artery disease or chronic heart failure $[3,4]$.

Besides risk factor management (specifically control or reduction of lipids, blood pressure, body weight, diabetes mellitus and cigarette smoking), the other core components of cardiac rehabilitation include nutritional and physical activity counseling, psychosocial interventions and exercise training [4]. In particular, exercise training is often the component being examined under the umbrella

\section{Biomed Central}


term 'cardiac rehabilitation', likely because of its duration and therefore the cost of the program [5].

Several systematic reviews over the past three decades have consistently demonstrated cardio-protective effects of exercise-based cardiac rehabilitation programs [6-9]. Exercise-based cardiac rehabilitation, compared to usual care, reduces all-cause mortality by $20 \%$ (95\% confidence interval, CI: $7 \%, 32 \%)$ and cardiac mortality 26\% (95\% CI: 4\%, 39\%) [8]. Risk factors such as total cholesterol, triglycerides, systolic blood pressure and self-reported smoking habits were also significantly reduced [8]. The pooled sample size for the most recent systematic review was 8,940 , most of whom had undergone at least two months of cardiac rehabilitation under supervision of professional exercise personnel [8]. This implies great involvement of economic cost in the delivery of cardiac rehabilitation.

Economic evaluation of cardiac rehabilitation has been reported since the 1980s. A systematic review of economic evaluation studies on cardiac rehabilitation, which identified 15 studies, was reported in 2005. Based on studies published between 1985 to 2004, supervised cardiac rehabilitation, compared to usual care, resulted in USD2,193 to USD28,193 per life year gained, and USD668 to USD16,118 per quality-adjusted life years(monetary values were 2004 US dollars) [10]. Most of the studies reviewed up to 2004 were based on prospective randomized controlled trials conducted much earlier than their published dates. Over the past five years, more economic evaluation studies emerged. These studies might involve patients who have undergone more recent medical therapies for coronary artery disease and chronic heart failure. Recent studies have also focused on comparisons among different modes of delivery of cardiac rehabilitation, such as programs that were outpatient-, inpatient- as well as home-based. Therefore it is timely to systematically review and summarize the evidence on cost-effectiveness of cardiac rehabilitation.

The overall objective of the current systematic review was to describe and summarize published economic evaluations of cardiac rehabilitation for comparing the costeffectiveness of different modes of delivery of cardiac rehabilitation. The specific aims were to compare the following modes of delivery:

(a) supervised cardiac rehabilitation versus no cardiac rehabilitation,

(b) supervised versus home-based cardiac rehabilitation,

(c) inpatient (not Phase I ward program, but residential Phase II program) versus outpatient cardiac rehabilitation, and

(d) home-based cardiac rehabilitation versus no cardiac rehabilitation.

In this review, cardiac rehabilitation is considered as consisting of at least exercise training sessions, as this is usually the component studied as well as being the main cost driver of cardiac rehabilitation programs.

\section{Methods}

\section{Search strategy}

Prior to developing the search strategy, "PICO" statements were used to address the specific aims of the systematic review (Table 1). The electronic databases of EMBASE, MEDLINE, NHS EED, PEDro and CINAHL was searched using the text word terms of 'economic evaluation,' 'cost', 'cost-effectiveness', 'cost-benefit' or 'costutility', and 'cardiac rehabilitation' up to May 2010. Hand searches of bibliographies of each reference followed to identify any additional publications. Unpublished or grey literature was not included.

\section{Selection criteria}

For the purpose of this review, the inclusion criteria were as follows:

- Economic evaluation study design that was either prospective alongside a clinical trial or based on modeling;

- Adult patients diagnosed with acute myocardial infarction (including post-infarction and after revascularization surgery or percutaneous coronary intervention for infarct), or chronic heart failure;

Table 1 PICO statements used to develop the search to address the four different modes of delivery

\begin{tabular}{|c|c|c|c|c|}
\hline PICO & (a) & (b) & (c) & (d) \\
\hline Population & $\begin{array}{l}\text { Patients diagnosed } \\
\text { with acute MI } \\
\text { or chronic HF }\end{array}$ & $\begin{array}{l}\text { Patients diagnosed } \\
\text { with acute Ml or } \\
\text { chronic HF }\end{array}$ & $\begin{array}{l}\text { Patients diagnosed } \\
\text { with acute Ml or } \\
\text { chronic HF }\end{array}$ & $\begin{array}{l}\text { Patients diagnosed } \\
\text { with acute Ml or } \\
\text { chronic HF }\end{array}$ \\
\hline Intervention & $\begin{array}{l}\text { Supervised } \\
\text { outpatient CR }\end{array}$ & $\begin{array}{l}\text { Supervised } \\
\text { outpatient CR }\end{array}$ & $\begin{array}{l}\text { Supervised } \\
\text { outpatient CR }\end{array}$ & Home-based CR \\
\hline Comparison & $\begin{array}{l}\text { Usual/standard care } \\
\text { (i.e., no CR) }\end{array}$ & Home-based CR & $\begin{array}{l}\text { Supervised } \\
\text { inpatient CR }\end{array}$ & $\begin{array}{l}\text { Usual/standard care } \\
\text { (i.e., no CR) }\end{array}$ \\
\hline Outcome & Cost-effectiveness & Cost-effectiveness & Cost-effectiveness & Cost-effectiveness \\
\hline
\end{tabular}

MI, myocardial infarction; $\mathrm{HF}$, heart failure; $\mathrm{CR}$, cardiac rehabilitation. 
- Intervention that included exercise-based cardiac rehabilitation;

- Study with at least one of four comparators listed in Table 1;

- Outcomes included either cost-effectiveness, costutility or cost-benefit analysis. Cost-minimization analysis was not included.

Articles were excluded if one of the elements of PICO (Table 1) was not met.

\section{Quality assessment}

The 10-item Drummond checklist was used to assess the methodological quality of the economic evaluation studies [11]. If the study met any of these 10 items, it would be considered as 'Yes', otherwise 'No' or 'Cannot tell' (Additional file 1: Appendix 1). The Drummond checklist provides a global assessment of the quality of evidence, but does not form the basis for accepting or rejecting articles.

\section{Data abstraction}

Two independent reviewers (JF and WPW) selected eligible publications initially based on titles and abstracts. Potentially relevant articles were abstracted using standardized data abstraction form. This form was also used for data synthesis. Any disagreement between the reviewers was resolved by consultation with a third reviewer (KHP).

\section{Results}

\section{Synthesis}

A total of 896 citations were retrieved based on the search strategy. Of the 62 articles retrieved for more detailed evaluation, only 20 were included. An additional two references from hand searches yielded a total of 22 [12-33] articles for review. Five articles were concerned with cost-minimization analyses, whilst one article included data from patients with stroke in its economic modelling. The remaining 16 articles included one article that addressed both centre-based cardiac rehabilitation versus no rehabilitation, and home-based cardiac rehabilitation versus no rehabilitation. Among the six foreign-language articles, three did not meet the inclusion criteria, two were editorials or commentaries and one was deemed irrelevant after reading through the full article. Therefore, only 16 articles were included. Figure 1 describes the reasons for not including the articles.

The majority of the articles clearly stated that they included patients after acute myocardial infarction, following revascularization surgery or percutaneous coronary interventions, or who had a diagnosis of chronic heart failure, and therefore satisfied the selection criterion on diagnosis. Two articles employed the same sample for analyses, involving patients with coronary artery disease, defined as acute myocardial infarction or angina pectoris $[25,27]$. One study included patients with coronary artery disease, defined as acute myocardial infarction $(75 \%$ and $79 \%$ respectively in both groups) or post-angioplasty (25\% and $21 \%$ respectively) [32]. In another study,

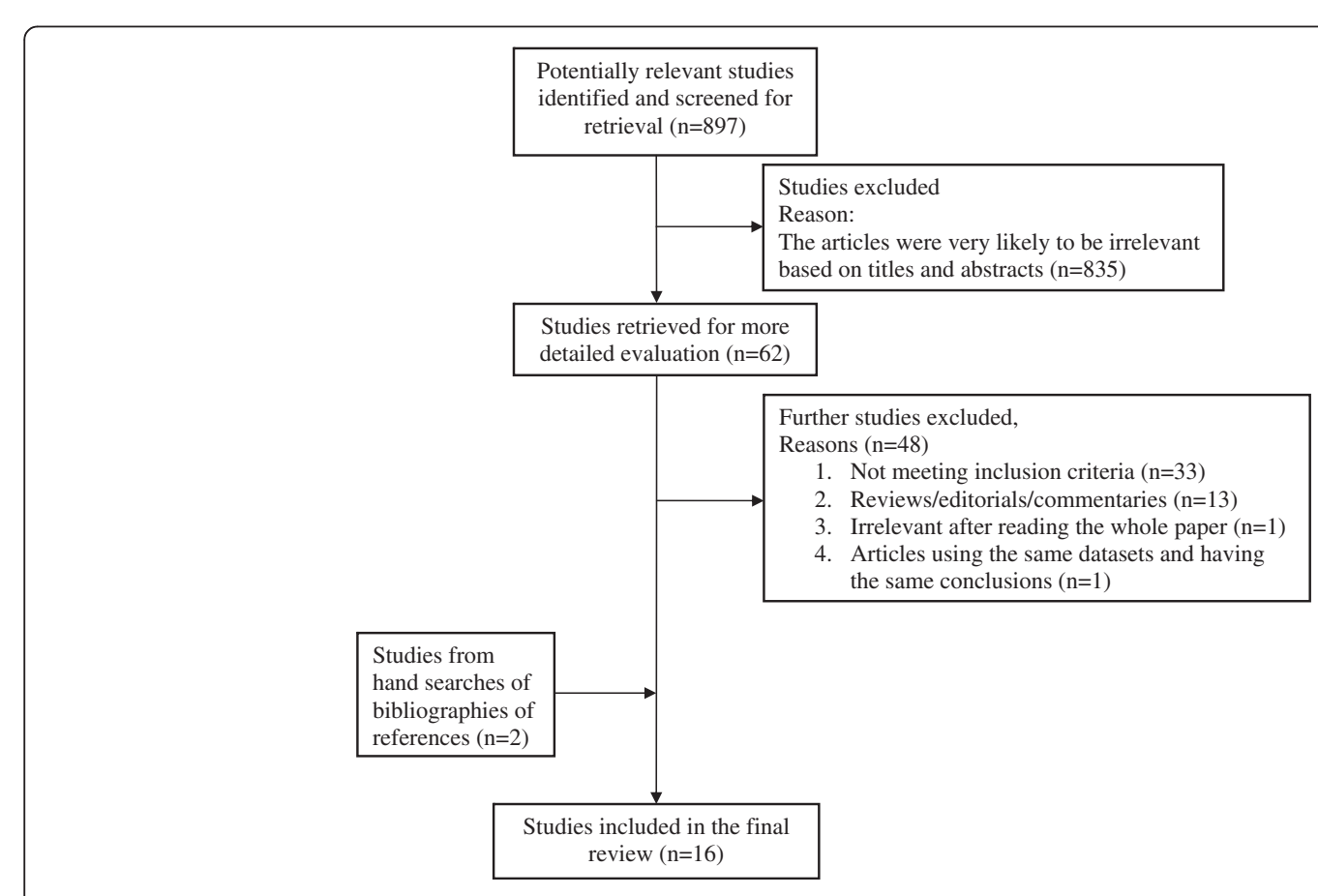

Figure 1 Flow of included studies. 
Table 2 Summary of economic evaluations comparing supervised centre-based cardiac rehabilitation (CR) vs no cardiac rehabilitation (No-CR)

\begin{tabular}{|c|c|c|c|c|c|}
\hline Author (Year) & Perspective & Patient populations & Study type & Currency, price year & Findings \\
\hline Levin et al. (1991) & Societal & $\mathrm{N}=305$ after $\mathrm{Ml}$ & CCA & Swedish kroner, ?year & CR: SEK73,500 less per patient \\
\hline Ades et al. 1992 & Patients/ payers & $\mathrm{N}=580$ after $\mathrm{MI} / \mathrm{CABG}$ & CCA & US dollars, 1991 & $\begin{array}{l}\text { CR: } \$ 739 \text { less in hospitalization } \\
\text { costs per patient }\end{array}$ \\
\hline Oldridge et al. (1993) & Societal & $\mathrm{N}=201$ after $\mathrm{Ml}$ & CUA/ modelling & US dollars, 1991 & $\begin{array}{l}\text { CR: } \$ 21,800 \text { per life-year } \\
\text { gained; } \$ 9,200 \text { per QALY } \\
\text { gained at } 1 \text { year }\end{array}$ \\
\hline Ades et al. (1997) & Patients/ Payers & Not applicable & Economic modeling & US dollars, 1995 & $\begin{array}{l}\text { CR: } \$ 4,950 \text { per year } \\
\text { of life saved }\end{array}$ \\
\hline Georgiou et al. (2001) & Societal & $\mathrm{N}=99$ with $\mathrm{HF}$ & CEA & US dollars, 1999 & $\begin{array}{l}\text { ICER }=\$ 1,773 \text { per life year } \\
\text { saved in favour of } C R\end{array}$ \\
\hline Marchionni et al. (2003) & $\begin{array}{l}\text { Government } \\
\text { or care providers }\end{array}$ & $\mathrm{N}=158$ with $\mathrm{Ml}$ & CCA & US dollars, 2000 & $\begin{array}{l}\text { CR: } \$ 21,298 \text { per patient vs } \\
\$ 12,433 \text { per patient in } \\
\text { No-CR group }\end{array}$ \\
\hline Yu et al. (2004) & Government & $\mathrm{N}=204$ after $\mathrm{Ml}$ or $\mathrm{PCl}$ & CUA & US dollars, ?year & $\begin{array}{l}\text { ICUR }=\$ 650 \text { per QALY } \\
\text { in favour of CR }\end{array}$ \\
\hline Huang et al. (2008) & Government & $N=4,324$ after $C A B G$ & CEA & US dollars, 1998 & $\begin{array}{l}\text { ICER }=13,887 \text { per year } \\
\text { of life saved } \\
\text { in favour of } C R\end{array}$ \\
\hline Dendale et al. (2008) & Health care payers & $\mathrm{N}=213$ after $\mathrm{PCl}$ & CEA & Euro, ?year & $\begin{array}{l}\text { CR: } 4,862 € \text { per patient } \\
\text { and } 5,498 € \text { per patient } \\
\text { in No-CR group }\end{array}$ \\
\hline
\end{tabular}

MI, myocardial infarction. $\mathrm{HF}$, heart failure. CABG, coronary artery bypass graft surgery. $\mathrm{PCl}$, percutaneous coronary intervention. CCA, cost-consequences analysis. CEA, cost-effectiveness analysis. CUA, cost-utility analysis. QALY, quality-adjusted life-years. ICER, incremental cost-effectiveness ratio. ICUR, incremental cost-utility ratio.

patients after acute myocardial infarction accounted for $39 \%$, chronic heart failure $22 \%$, angina $45 \%$, arrhythimias $59 \%$, and valvular disease $26 \%$ [30].

The quality of these articles varied. Articles fulfilled two to nine items on the Drummond checklist, with none of them meeting all the items (Additional file 1: Appendix 1). Table 2 summarizes the economic evaluations reported in these studies (details in Additional file 2: Appendix 2). Five of these studies were cost-minimization analysis, and therefore were strictly not considered as full economic evaluations [11].

\section{Supervised (or centre-based) cardiac rehabilitation versus} no cardiac rehabilitation (usual/standard care)

A total of nine studies examined the cost-effectiveness of supervised centre-based cardiac rehabilitation compared to no cardiac rehabilitation. Most of the economic studies were conducted prospectively alongside randomized controlled trials (RCT) [14,16-18], whilst three studies used modeling to derive long-term cost-effectiveness [14-16]. All the studies suggested that cardiac rehabilitation supervised at a facility compared to no cardiac rehabilitation was cost-saving $[12,13,20]$, cost-effective $[14,17,19]$ and a dominant strategy (that is, less cost, more effective) $[16,18]$. However, cost-effectiveness could become less because of escalating medical costs, as demonstrated by one modeling study [15].

\section{Supervised (or centre-based) versus home-based cardiac rehabilitation}

Among 10 studies, six yielded no significant differences in the clinical outcome measures, and were therefore technically considered cost-minimization analyses $[17,21,23,24,28,33]$. Of the remaining four studies, one study employed economic modelling in cost-effectiveness analysis, using data from patients with cardiovascular disease, defined as 'self-report of previous heart attack, stroke, or other heart disease' [22]. Among the three included studies (Table 3), one showed that centrebased strategy was dominant compared to home-based rehabilitation [27], whilst two studies demonstrated no difference in cost-effectiveness [25,26]. In one of the cost-minimization analyses, cost to the government (taxation-based health care system) was greater with home-based program than centre-based program, likely due to frequent home visits by hospital staff [28]. The definition of 'home-based program' varied among the three studies, involving combinations of home visits $[25,26]$ and decreased frequency of centre-based rehabilitation attendances [25,27].

\section{Inpatient versus outpatient cardiac rehabilitation}

The only study that evaluated cost-effectiveness between inpatient and outpatient cardiac rehabilitation demonstrated no significant difference [29] (Table 4). 
Table 3 Summary of economic evaluations comparing supervised centre-based cardiac rehabilitation (CR) vs home-based cardiac rehabilitation (HCR)*

\begin{tabular}{llllll}
\hline Author (Year) & Perspective & Patient populations & Study type & Currency, price year & Findings \\
\hline Reid et al. (2005) & Health system & $\mathrm{N}=392 \mathrm{CAD}$ & $\mathrm{CCA}$ & US dollars, 2004 & HCR: $\$ 5,267$ per patient \\
& & & & CR: $\$ 5,132$ per patient; no difference \\
Taylor et al. (2007) & Societal & $\mathrm{N}=80 \mathrm{Ml}$ & CUA & Sterling pounds, 2002-3 & $\begin{array}{l}\text { ICUR }=-£ 644 \text { per QALY in favour } \\
\text { of CR but not significantly different }\end{array}$ \\
Papadakis et al. (2008) & Health system & $\mathrm{N}=392$ CAD & CUA & US dollars, 2004 & ICUR $=\$ 11,400$ per QALY in favour of CR
\end{tabular}

MI, myocardial infarction. CAD, coronary artery disease. CCA, cost-consequences analysis. CUA, cost-utility analysis. QALY, quality-adjusted life-years. ICUR, incremental cost-utility ratio. * ${ }^{*}$ cost-minimization analyses were not included in this table (refer to Additional file 2: Appendix 2 for details).

\section{Home-based cardiac rehabilitation versus no cardiac rehabilitation (usual/standard care)}

Four studies considered the cost-effectiveness of homebased program compared to no cardiac rehabilitation program. Home-based program was considered affordable [32] and more cost-effective than no cardiac rehabilitation [17]. Two studies demonstrated cost-savings $[30,31]$ with home-based program. Of interest was the internet-based program by one of these studies [31].

\section{Discussion}

This systematic review summarizes the cost-effectiveness of cardiac rehabilitation compared to no cardiac rehabilitation, for patients after myocardial infarction, revascularization surgery or percutaneous coronary interventions, as well as those with chronic heart failure. Pooling of results is not possible given the heterogeneity in perspectives, health systems, study designs, details of cardiac rehabilitation interventions and types of patients that exist among the studies included in this review. However, we contend that these studies provide sufficient evidence for policy development concerning cardiac rehabilitation.

Inclusion of a supervised outpatient cardiac rehabilitation program is clearly more cost-effective than not including cardiac rehabilitation program ("usual or standard care") into the overall management of patients after myocardial infarction or those with chronic heart failure. The centre-based programs consisted of exercise-based sessions, three times a week, over a period of 8 to 12 weeks. In addition, risk factor management and other multidisciplinary input were included in half of these studies.

Four of the nine studies were economic evaluations alongside prospective randomized controlled trials $[14,16-$ 18]. Two of these studies examined cost-effectiveness from the societal perspective within differing health systems $[14,16]$. In the Canadian health system, cardiac rehabilitation compared to usual care had an incremental cost-effectiveness of USD9,200 per quality-adjusted lifeyear (QALY) gained as well as USD21,800 per life-year saved (1991 US dollars) at 12 months [14]. In the United States' private health care system, cardiac rehabilitation was the dominant strategy compared to no cardiac rehabilitation with $\$ 1,773$ (2001 US dollars) per life-year saved at 14 months [16]. Recent economic studies with non-randomized group allocation designs corroborated this observation, for example, an incremental costeffectiveness ratio of $\$ 13,887$ per life-year saved (1998 US dollars) was estimated based on Medicare expenditures for American patients undergoing cardiac rehabilitation; these patients had concomitant end-stage renal failure requiring haemodialysis and post-coronary artery bypass graft surgery [19]. In Belgian patients following percutaneous coronary interventions, cardiac rehabilitation led to reduced hospitalization and revascularization surgery, and subsequently cost (published in 2008, in euros) [20]. One economic modeling study suggested that cost savings could become less over the years as a result of rising health care costs [15]. Much of the cost escalation could be attributed to the high costs of cardiac investigations and surgery, in addition to the personnel-intense multidisciplinary cardiac rehabilitation program [26]. Therefore, home-based programs have been touted as a cost-effective alternative.

Comparisons between home-based and centre-based programs were predominantly cost-minimization studies $[17,21,23,24,28,33]$. In all these studies, the consequences of both alternatives were equivalent, so the authors sought to only compare their costs. Despite different settings, these studies consistently showed that home- and centrebased cardiac rehabilitation to be similar in cost.

Although all 13 studies (including cost-minimization analyses) on home-based cardiac rehabilitation, compared to either supervised centre-based programs or no cardiac

Table 4 Summary of economic evaluations comparing supervised centre-based inpatient cardiac rehabilitation (ICR) vs supervised centre-based outpatient cardiac rehabilitation (CR)

\begin{tabular}{|c|c|c|c|c|c|}
\hline Author (Year) & Perspective & Patient populations & Study type & Currency, price year & Findings \\
\hline Schweikert et al. (2009) & Societal & $\mathrm{N}=147 \mathrm{Ml}$ & CEA/CUA & Euro, 2006 & $\begin{array}{l}\text { ICER }=-165,276 € \text { per QALY in favour of CR, } \\
\text { although no significant }\end{array}$ \\
\hline
\end{tabular}


Table 5 Summary of economic evaluations comparing home-based cardiac rehabilitation (HCR) and no cardiac rehabilitation (No-CR)

\begin{tabular}{|c|c|c|c|c|c|}
\hline Author (Year) & Perspective & Patient populations & Study type & Currency, price year & Findings \\
\hline Wheeler et al. (2003) & Patients/ payers & $\mathrm{N}=452$ women with $\mathrm{Ml}, \mathrm{HF}$, etc. & CCA & US dollars, 2000 & $\begin{array}{l}\text { HCR: } 49 \% \text { lower inpatient cost; } \\
46 \% \text { fewer inpatient days }\end{array}$ \\
\hline Southard et al. (2003) & Patients & $\mathrm{N}=104 \mathrm{Ml}, \mathrm{CABG}, \mathrm{HF}$ & $\mathrm{CCA} / \mathrm{CBA}$ & US dollars, ?year & $\begin{array}{l}\text { HCR: cost } \$ 1,418 \text { less with } \\
213 \% \text { return on investment }\end{array}$ \\
\hline \multirow[t]{2}{*}{ Marchionni et al. (2003) } & $\begin{array}{l}\text { Government } \\
\text { or care providers }\end{array}$ & $\mathrm{N}=153 \mathrm{Ml}$ & CCA & US dollars, 2000 & $\begin{array}{l}\text { HCR: } \$ 13,246 \text { per patient; } \\
\text { better outcomes }\end{array}$ \\
\hline & & & & & No-CR: $\$ 12,433$ per patient \\
\hline Salvetti et al. (2008) & Health providers & $N=39 C A D$ & CCA & US dollars, ?year & HCR: \$502.71 more per patient \\
\hline
\end{tabular}

rehabilitation, have demonstrated home-based model to be cost-effective or cost-saving, the contents of the homebased programs varied widely. The contents of homebased program ranged from actual exercise sessions at home [21,22,33], frequent home visits by case managers and physicians [24-26,28], to reduced or more spaced-out attendances at the centre $[17,23,25,27]$. Exercise participation has to be regular to be effective. The option of reduced or spaced-out attendances at the centre is primarily to encourage the patients to continue with the exercises at home, whilst providing opportunity to return to the centre for reinforcement, monitoring and evaluation. One program was internet-based, requiring computer literacy, internet access at home and frequent log-ons to the web site to update on completion of exercises [31].

Early studies (before 2005) tended to demonstrate that home-based programs were more cost-effective and costsaving than centre-based ones [17,21-24,33]. Sensitivity analyses in some of these studies have shown no change to the conclusion despite taking the worst-case scenario [17] or varying variables such as costs [24], readmission rates [24], patients' travelling time [24], exercise adherence [22] and discounting rates [22,24]. Home-based programs in these studies were varied, including program with reduced sessions at the centre to exercise program conducted entirely at home with or without frequent home visits by health care professionals (see Table 3). However, the recent studies have shown otherwise [25-28]. Three recent studies demonstrated no significant difference in the cost-effectiveness of centre- versus home-based programs $[25,26,28]$. In one study, sensitivity analyses by taking the upper estimate of UK hospital rehabilitation costs did not alter the conclusion, because cardiac-related costs far exceeded rehabilitation costs [26]. All three economic evaluations were conducted alongside randomized controlled trials, within a taxationbased health care system (Canada and UK) and involved multiple home visits by health care professionals (case managers, physicians and rehab nurses). One recent study demonstrated greater quality adjusted life-year gained among participants in centre-based program than those in home-based program [27]. The "home-based" program in this study was 33 cardiac rehabilitation sessions spread across 12 months, whereas the centre-based program was the same 33 sessions conducted over 3 months. Interestingly, these authors found that the spread-out program was more cost-effective among women whilst the centrebased program was more cost-effective among men [27]. Thus, the cost-effectiveness of the so-called home-based cardiac rehabilitation program depends heavily upon its contents as well as patient profiles. Policy decision makers, and payers or purchasers of cardiac rehabilitation services, should take into consideration of the model of homebased programs when considering resource allocation. The use of information and communication technology and internet-based programs should be explored, and therefore further studies could compare internet- versus centre-based programs in terms of cost-effectiveness.

\section{Limitations}

None of the 16 articles met all of Drummond's 10-item checklist (Table 2). Articles were dated as early as 1985 and as recently as 2009 , with 13 of the articles published in the last 10 years. Majority of the studies collected and analyzed only direct medical costs. Few studies considered sensitivity analysis to account for uncertainty in costs and consequences. Although none of the foreign-language articles were included, none met the inclusion criteria for review. Publication bias cannot be excluded as almost all the economic evaluations demonstrated cost-effectiveness.

\section{Conclusions}

In conclusion, evidence exists that supports the inclusion of supervised outpatient centre-based or home-based cardiac rehabilitation compared to no cardiac rehabilitation in patients after myocardial infarction, revascularization surgery or percutaneous coronary interventions, as well as those with chronic heart failure. Based on the reviewed articles, it would appear that the costs and outcomes of home- versus supervised centre-based cardiac 
rehabilitation were no different. Therefore the choice of the mode of delivery (home- versus centre-based) should be left to purchasers and patients. To the policy decision makers, there could be possible economic advantage of home-based program over centre-based ones. However, the details of what constitute "home-based program" are important.

\section{Additional files}

Additional file 1: Appendix 1. Quality assessment with the 10-item Drummond checklist [11].

Additional file 2: Appendix 1. Summary of Studies on Economic Evaluations of Cardiac Rehabilitation (CR).

\section{Competing interests}

The authors declare that they have no competing interests.

\section{Authors' contributions}

WPW and JF performed article search and screened the abstracts. KHP resolved any disagreements arising from the primary reviewers' interpretations of the articles and provided input to the manuscript. JL provided input to the interpretation of the review and discussion. All authors read and approved the final manuscript.

\section{Acknowledgements}

We thanked Brian Choi for input to the initial phase of the systematic review. At the time of this work, JF and KHP were with the Health Services Research and Evaluation Division and JL was with the Primary and Community Care Division, Ministry of Health.

\section{Author details}

${ }^{1}$ Academic Programmes Division, Singapore Institute of Technology, 25 North Bridge Road, Singapore, Singapore. ${ }^{2}$ Primary \& Community Care Division, Ministry of Health, 16 College Road, Singapore, Singapore. ${ }^{3}$ Optumlnsight, 370-372 Norton Street, New South Wales, Australia. ${ }^{4}$ Performance and Technology Assessment Division, Ministry of Health, College Road, Singapore, Singapore. ${ }^{5}$ Fortis Healthcare Singapore, 180 Clemenceau Avenue, Singapore, Singapore.

Received: 27 July 2011 Accepted: 24 July 2012

Published: 8 August 2012

\section{References}

1. Yusuf S, Reddy S, Ounpuu S, Anand S: Global burden of cardiovascular diseases: part l: general considerations, the epidemiologic transition, risk factors, and impact of urbanization. Circulation 2001, 104(22):2746-2753.

2. Levenson JW, Skerrett PJ, Gaziano JM: Reducing the global burden of cardiovascular disease: the role of risk factors. Prev Cardiol 2002, 5(4):188-199.

3. Wenger NK, Froelicher ES, Smith LK, Ades PA, Berra K, Blumenthal JA, Certo CME, Dattilo AM, Davis D, DeBusk RF, et al: Cardiac Rehabilitation. Clinical Practice Guideline No. 17. Rockville, MD: U.S. Department of Health and Human Services, Public Health Service, Agency for Health Care Policy and Research and the National Heart, Lung, and Blood Institute; 1995.

4. Balady GJ, Williams MA, Ades PA, Bittner V, Comoss P, Foody JM, Franklin B, Sanderson B, Southard D: Core components of cardiac rehabilitation/ secondary prevention programs: 2007 update: a scientific statement from the American Heart Association Exercise, Cardiac Rehabilitation, and Prevention Committee, the Council on Clinical Cardiology; the Councils on Cardiovascular Nursing, Epidemiology and Prevention, and Nutrition, Physical Activity, and Metabolism; and the American Association of Cardiovascular and Pulmonary Rehabilitation. Circulation 2007, 115(20):2675-2682

5. Dafoe W, Arthur H, Stokes H, Morrin L, Beaton L: Universal access: but when? Treating the right patient at the right time: access to cardiac rehabilitation. Can J Cardiol 2006, 22(11):905-911.
6. O'Connor GT, Buring JE, Yusuf S, Goldhaber SZ, Olmstead EM, Paffenbarger RS Jr, Hennekens CH: An overview of randomized trials of rehabilitation with exercise after myocardial infarction. Circulation 1989, 80(2):234-244.

7. Oldridge NB, Guyatt GH, Fischer ME, Rimm AA: Cardiac rehabilitation after myocardial infarction. Combined experience of randomized clinical trials. JAMA 1988, 260(7):945-950.

8. Taylor RS, Brown A, Ebrahim S, Jolliffe J, Noorani H, Rees K, Skidmore B, Stone JA, Thompson DR, Oldridge N: Exercise-based rehabilitation for patients with coronary heart disease: systematic review and metaanalysis of randomized controlled trials. Am J Med 2004, 116(10):682-692

9. Heran BS, Chen JM, Ebrahim S, Moxham T, Oldridge N, Rees K, Thompson DR, Taylor RS: Exercise-based cardiac rehabilitation for coronary heart disease. Cochrane Database Syst Rev 2011, 7:CD001800

10. Papadakis S, Oldridge NB, Coyle D, Mayhew A, Reid RD, Beaton L, Dafoe WA, Angus D: Economic evaluation of cardiac rehabilitation: a systematic review. Eur J Cardiovasc Prev Rehabil 2005, 12(6):513-520.

11. Drummond MF, Sculpher MJ, Torrance GW, O'Brien BJ, Stoddart GL: Methods for the economic evaluation of health care programmes. 3rd edition. New York: Oxford University Press; 2005.

12. Levin LA, Perk J, Hedback B: Cardiac rehabilitation-a cost analysis. J Intern Med 1991, 230(5):427-434.

13. Ades PA, Huang D, Weaver SO: Cardiac rehabilitation participation predicts lower rehospitalization costs. Am Heart J 1992, 123(4 Pt 1):916-921.

14. Oldridge N, Furlong W, Feeny D, Torrance G, Guyatt G, Crowe J, Jones N: Economic evaluation of cardiac rehabilitation soon after acute myocardial infarction. Am J Cardiol 1993, 72(2):154-161.

15. Ades PA, Pashkow FJ, Nestor JR: Cost-effectiveness of cardiac rehabilitation after myocardial infarction. J Cardiopulm Rehabil 1997, 17(4):222-231.

16. Georgiou D, Chen Y, Appadoo S, Belardinelli R, Greene R, Parides MK, Glied $\mathrm{S}$ : Cost-effectiveness analysis of long-term moderate exercise training in chronic heart failure. Am J Cardiol 2001, 87(8):984-988. A984.

17. Marchionni N, Fattirolli F, Fumagalli S, Oldridge N, Del Lungo F, Morosi L, Burgisser C, Masotti G: Improved exercise tolerance and quality of life with cardiac rehabilitation of older patients after myocardial infarction: results of a randomized, controlled trial. Circulation 2003, 107(17):2201-2206.

18. Yu CM, Lau CP, Chau J, McGhee S, Kong SL, Cheung BM, Li LS: A short course of cardiac rehabilitation programme is highly cost effective in improving long-term quality of life in patients with recent myocardial infarction or percutaneous coronary intervention. Arch Phys Med Rehabil 2004, 85(12):1915-1922.

19. Huang Y, Zhang R, Culler SD, Kutner NG: Costs and effectiveness of cardiac rehabilitation for dialysis patients following coronary bypass. Kidney Int 2008, 74(8):1079-1084.

20. Dendale P, Hansen D, Berger J, Lamotte M: Long-term cost-benefit ratio of cardiac rehabilitation after percutaneous coronary intervention. Acta Cardiol 2008, 63(4):451-456.

21. DeBusk RF, Haskell WL, Miller NH, Berra K, Taylor CB, Berger WE 3rd, Lew H: Medically directed at-home rehabilitation soon after clinically uncomplicated acute myocardial infarction: a new model for patient care. Am J Cardiol 1985, 55(4):251-257.

22. Lowensteyn I, Coupal L, Zowall H, Grover SA: The cost-effectiveness of exercise training for the primary and secondary prevention of cardiovascular disease. J Cardiopulm Rehabil 2000, 20(3):147-155.

23. Carlson JJ, Johnson JA, Franklin BA, VanderLaan RL: Program participation, exercise adherence, cardiovascular outcomes, and program cost of traditional versus modified cardiac rehabilitation. Am J Cardiol 2000, 86(1):17-23.

24. Collins L, Scuffham P, Gargett S: Cost-analysis of gym-based versus home-based cardiac rehabilitation programs. Aust Health Rev 2001 24(1):51-61.

25. Reid RD, Dafoe WA, Morrin L, Mayhew A, Papadakis S, Beaton L, Oldridge $N B$, Coyle D, Wells GA: Impact of program duration and contact frequency on efficacy and cost of cardiac rehabilitation: results of a randomized trial. Am Heart J 2005, 149(5):862-868.

26. Taylor RS, Watt A, Dalal HM, Evans PH, Campbell JL, Read KL, Mourant AJ, Wingham J, Thompson DR, Pereira Gray DJ: Home-based cardiac rehabilitation versus hospital-based rehabilitation: a cost effectiveness analysis. Int J Cardio/ 2007, 119(2):196-201. 
27. Papadakis S, Reid RD, Coyle D, Beaton L, Angus D, Oldridge N: Costeffectiveness of cardiac rehabilitation program delivery models in patients at varying cardiac risk, reason for referral, and sex. Eur J Cardiovasc Prev Rehabil 2008, 15(3):347-353.

28. Jolly K, Lip GY, Taylor RS, Raftery J, Mant J, Lane D, Greenfield S, Stevens A: The Birmingham Rehabilitation Uptake Maximisation study (BRUM): a randomised controlled trial comparing home-based with centre-based cardiac rehabilitation. Heart 2009, 95(1):36-42

29. Schweikert B, Hahmann H, Steinacker JM, Imhof A, Muche R, Koenig W, Liu $Y$, Leidl R: Intervention study shows outpatient cardiac rehabilitation to be economically at least as attractive as inpatient rehabilitation. Clin Res Cardiol 2009, 98(12):787-795.

30. Wheeler JR, Janz NK, Dodge JA: Can a disease self-management program reduce health care costs? The case of older women with heart disease. Med Care 2003, 41(6):706-715.

31. Southard BH, Southard DR, Nuckolls J: Clinical trial of an Internet-based case management system for secondary prevention of heart disease. J Cardiopulm Rehabil 2003, 23(5):341-348.

32. Salvetti XM, Oliveira JA, Servantes DM, Vincenzo de Paola AA: How much do the benefits cost? Effects of a home-based training programme on cardiovascular fitness, quality of life, programme cost and adherence for patients with coronary disease. Clin Rehabil 2008, 22(10-11):987-996.

33. Hall JP, Wiseman VL, King MT, Ross DL, Kovoor P, Zecchin RP, Moir FM, Denniss AR: Economic evaluation of a randomised trial of early return to normal activities versus cardiac rehabilitation after acute myocardial infarction. Heart Lung Circ 2002, 11(1):10-18.

doi:10.1186/1472-6963-12-243

Cite this article as: Wong et al:: A systematic review of economic evaluations of cardiac rehabilitation. BMC Health Services Research 2012 $12: 243$.

\section{Submit your next manuscript to BioMed Central and take full advantage of:}

- Convenient online submission

- Thorough peer review

- No space constraints or color figure charges

- Immediate publication on acceptance

- Inclusion in PubMed, CAS, Scopus and Google Scholar

- Research which is freely available for redistribution 